\title{
Biofilm Formation Between Bacillus Subtilis and Escherichia Coli K-12 Strains at Acidic and Oxidative Stress
}

\author{
Ivo Ganchev \\ Department of General Microbiology, The Stephan Angeloff Institute of Microbiology, Bulgarian Academy of Sciences, Sofia, Bulgaria \\ Email address: \\ ivotg@abv.bg \\ To cite this article: \\ Ivo Ganchev. Biofilm Formation Between Bacillus Subtilis and Escherichia Coli K-12 Strains at Acidic and Oxidative Stress. Science \\ Journal of Chemistry. Vol. 7, No. 1, 2019, pp. 15-18. doi: 10.11648/j.sjc.20190701.13
}

Received: September 30, 2018; Accepted: October 24, 2018; Published: April 18, 2019

\begin{abstract}
Biofilms constitute the predominant microbial style of life in natural and engineered ecosystems. At the harsh environmental conditions microorganisms accumulate reactive oxygen species (ROS), potentially encountering a dangerous condition called oxidative stress. An investigation into the mechanisms activated by biofilms in response to different oxidative stress levels could have important consequences from ecological and economic points of view, and could be exploited to propose alternative strategies to control microbial virulence and deterioration. In this respect, the aim if this study is to evaluate the influence temperature and $\mathrm{pH}$ of the medium, its osmolality and the presence of heavy metal ions on the growth of the biomass of biofilm formed by B. subtilis 170 and E. coli K- 12 strains and their relationship in them. This study was used the methods for a static cultivation of biofilm by co-cultures of B. subtilis 170 and E. coli K- 12 strains and determination of colony forming units in their structures to evaluate of the relationships between them. The results of the present study show that temperature of $20^{\circ} \mathrm{C}$ and $\mathrm{pH}$-value in the range of 5.0-6.0 help to maximum growth of biomass of biofilm formed by cocultivation of B. subtilis 170 and E. coli 1655 strains. The competitive relationships are observed at a temperature of $20^{\circ} \mathrm{C}$, at $\mathrm{pH}$-value in the range from 5.0 to 6.0 at low osmolality of the medium of 100 to $150 \mathrm{mM}$, at content of $\mathrm{Fe}^{+2}$ from $5 \mu \mathrm{M}$ to 100 $\mu \mathrm{M}$. The increase of the temperature above $30^{\circ} \mathrm{C}$ and the $\mathrm{pH}$ of the medium, the high osmolality of $200 \mathrm{mM}$ triggers antagonistic interactions between B. subtilis 170 and E. coli K- 12 strains, while at content of Fe ${ }^{+2}$ of $50 \mu \mathrm{M}$ was observed symbiosis in the structure of biofilms in this study.
\end{abstract}

Keywords: B. Subtilis 170, E. Coli 1655, Biofilm, Competition, Antagonism

\section{Introduction}

Bacteria were distributed in nature in the form of biofilms that are formed with the participation of two or more species [1-3]. The basis of their formation and their resistance toward various effects of the environment in the nature stand interactions between microbial species that include competition for nutrients of the composition of the environment, symbiosis and antagonism [2]. Therefore, the structure of biofilms and the composition of the microbial community in them are determined by the fluctuations in values of environmental factors [2-4].

Harsh environmental conditions such as high temperature, osmolality and $\mathrm{pH}$ of the medium, presence of heavy metal ions $\left(\mathrm{Fe}^{2+}\right.$ or $\mathrm{Fe}^{3+}$ or $\left.\mathrm{Cu}^{+}\right)$creates conditions for formation and accumulation of intracellular free radicals such as superoxide anion, hydrogen peroxide, singlet oxygen, hydroxyl radicals (oxidative stress), which in the high (lethal) concentrations have a cytotoxic effect and prevent biofilm formation process. Main mechanisms for protection of microbial species against their impact during the formation of biofilms is concluded in the presence of complex genetically regulatory network, responsible for the transition of cells from plankton state to attached mode of existence, and the formation of extracellular matrix, whose content is dominated by extracellular polysaccharides [5].

The aim if this study is to evaluate the influence temperature and $\mathrm{pH}$ of the medium, its osmolality and the presence of heavy metal ions on the growth of the biomass of biofilm formed by B. subtilis 170 and E. coli K- 12 strains 
and their relationship in them.

\section{Material and Methods}

\subsection{Bacterial Strains}

In this study were used B. subtilis 170 from collection, deposited in National Bank of Industrial Microorganisms and Cell Cultures, Sofia, Bulgaria, and E. coli 1655 from the collection of the Institute of Molecular Biotechnology, Jena, Germany. All strains were inoculated into $9 \mathrm{ml}$ of a liquid culture medium and incubated at $37^{\circ} \mathrm{C}$ for a period of 18 hours before the beginning of each determination.

\subsection{Method of Static Cultivating of Biofilms}

Liquid cultures were diluted in $5 \mathrm{ml}$ medium M63 in different ratio between $\mathrm{KH}_{2} \mathrm{PO}_{4}$ and $\mathrm{K}_{2} \mathrm{HPO}_{4}$, so that the $\mathrm{pH}$ of the medium to be $5.0 ; 6.0 ; 7.0 ; 8.0$. Study of influence of the temperature was carried out by incubating the cultures at $20^{\circ} \mathrm{C}, 30^{\circ} \mathrm{C}, 35^{\circ} \mathrm{C}$ and $40^{\circ} \mathrm{C}$ in medium M63 $(0.02 \mathrm{M}$ $\mathrm{KH}_{2} \mathrm{PO}_{4}, 0.04 \mathrm{M} \mathrm{K}_{2} \mathrm{HPO}_{4}, 0.02 \mathrm{M}\left(\mathrm{NH}_{4}\right)_{2} \mathrm{SO}_{4}, 0.1 \mathrm{mM}$ $\mathrm{MgSO}_{4}$ and $0.04 \mathrm{M}$ glucose).

Immediately after that was carried cultivation of biofilms in environments $\mathrm{M} 63$, containing $\mathrm{NaCl}$ of $100 \mathrm{mM}, 150 \mathrm{mM}$ and $200 \mathrm{mM}$ for taking into account the effects of osmolality on their growth. This was followed by carrying out a series of cultivation of biofilms in modified M63 medium to which is add $\mathrm{FeSO}_{4} \cdot 7 \mathrm{H}_{2} \mathrm{O}$, so that the content of $\mathrm{Fe}^{+2}$ to be $5 \mu \mathrm{M}, 50$ $\mu \mathrm{M}$ and $100 \mu \mathrm{M}$.

\subsection{Determination of Biomass Growth of Biofilms}

After incubation at $20^{\circ} \mathrm{C}$ for $24 \mathrm{~h}$ from each well separated carefully culture medium, after washing three times with saline solution staining of biofilms in half of the wells was carried out with $200 \mu \mathrm{l} 0,1 \%$ solution of crystal violet over a period of $15 \mathrm{~min}$, gently release and washing of dye in each well, then were added $200 \mu \mathrm{l}$ of $70 \%$ ethanol. Immediately after that it was determinated the optical density at $540 \mathrm{~nm}$ on "ELLIZA Reader ELTA 90".

\subsection{Determining of Number of Colonies in the Biofilms}

In the second half of the wells were added $200 \mu 10.85 \%$ sodium chloride solution. Using a sterile knife the biofilm was separated carefully. For each variant were made in 6 wells. Solutions with a release biofilm were collected in sterile eppendorff tubes. The number of colonies in the biofilms was determined according to the method of Koch [6] after inoculation on Meat Peptone Agar (NCIPD-Bull Bio, Sofia, Bulgaria) to evaluate of total number of colonies and on MacConkey agar (NCIPD-Bull Bio, Sofia, Bulgaria) for counting of number of colonies of E. coli 1655 strain.

\subsection{Statistical Treatment of Results}

All experiments were performed three times, presented results represent the average of three independent each other determinations. It was used a Student test, the differences of individual values were considered statistically significant at $\mathrm{p}$ $<0.05$.

\section{Results and Discussion}

Biofilms, which are formed by the participation of different bacterial species are highly distributed in nature. In the process of their forming establish different relationships between microorganisms that include competition for nutrients of the composition of the medium, antagonism or symbiosis. The process of formation of these organized structures on different surfaces strongly conditioned on the fluctuations in environmental factors [1].

The strains of the B. subtilis and E. coli species during the process of independent and co-culturing of biofilms maintain intracellular $\mathrm{pH}$ in narrow range from $\mathrm{pH} 7,2$ to $\mathrm{pH} 7,8$ at changing the $\mathrm{pH}$ of culture medium from 5.0 to 8,0 (Figure 1). The $\mathrm{pH}$ - value of the medium in the range of from $\mathrm{pH} 5,0$ to $\mathrm{pH} 6,0$ provides the presence of cells of E. coli K-121655 strain in the structure of the biofilm in association with B. subtilis 170 strains, which may be associated with the presence of potassium ions that contribute to the sustainability of cells against acid stress. However, the percentage of their population in the resulting biofilms is relatively small compared to the number of colonies of $\mathrm{B}$. subtilis 170 strain, which indicates a competitive relationship (Table 1).

Table 1. Influence of the $p H$ and temperature on the number of colonies of B. subtilis 170 and E. coli K-12 1655 strains in the structure of monospecies and mixed biofilms.

\begin{tabular}{|c|c|c|c|c|c|}
\hline \multirow{2}{*}{ № } & \multirow{2}{*}{ pH of medium } & \multirow{2}{*}{$\begin{array}{l}\text { Number in biofilms of } B \text {. subtilis } 170 \\
\text { cfu/ml }\end{array}$} & \multirow{2}{*}{$\begin{array}{l}\text { Number in biofilms of } E \text {. coli } \mathrm{K}-12 \\
1655, \mathrm{cfu} / \mathrm{ml}\end{array}$} & \multicolumn{2}{|c|}{ Number in mixed biofilms cfu/ml } \\
\hline & & & & B. subtilis 170 & E. coli K-12 1655 \\
\hline 1. & 5,0 & $9,05 \pm 0,18 \cdot 10^{6}$ & $1,62 \pm 0,12 \cdot 10^{6}$ & $9,55 \pm 0,13.10^{6}$ & $3,16 \pm 0,12 \cdot 10^{6}$ \\
\hline 2. & 6,0 & $8,11 \pm 0,07.10^{6}$ & $0,26 \pm 0,03 \cdot 10^{6}$ & $35,91 \pm 0,05 \cdot 10^{6}$ & $0,40 \pm 0,05.10^{6}$ \\
\hline 3. & 7,0 & $0,56 \pm 0,07 \cdot 10^{6}$ & 0 & $10,95 \pm 0,13 \cdot 10^{6}$ & 0 \\
\hline 4. & 8,0 & $0,23 \pm 0,03 \cdot 10^{6}$ & 0 & $6,18 \pm 0,20 \cdot 10^{6}$ & 0 \\
\hline
\end{tabular}

\begin{tabular}{|c|c|c|c|c|c|}
\hline \multirow{2}{*}{ № } & \multirow{2}{*}{ Temperature, ${ }^{\circ} \mathrm{C}$} & \multirow{2}{*}{$\begin{array}{l}\text { Number in biofilms of } B . \\
\text { subtilis } 170 \mathrm{cfu} / \mathrm{ml}\end{array}$} & \multirow{2}{*}{$\begin{array}{l}\text { Number in biofilms of E. coli K- } \\
121655, \mathrm{cfu} / \mathrm{ml}\end{array}$} & \multicolumn{2}{|c|}{ Number in mixed biofilms cfu/ml } \\
\hline & & & & B. subtilis 170 & E. coli K-12 1655 \\
\hline 1. & 20 & $6.65 \pm 0.1 .10^{6}$ & $0,4 \pm 0.0 .10^{6}$ & $46.31 \pm 0.33 .10^{6}$ & $6.01 \pm 0.03 .10^{6}$ \\
\hline 2. & 30 & $7.06 \pm 0.07 .10^{6}$ & 0 & $32,4 \pm 0.13 \cdot 10^{6}$ & 0 \\
\hline 3. & 35 & $0.63 \pm 0.05 .10^{6}$ & 0 & $4.65 \pm 0.05 .10^{6}$ & 0 \\
\hline 4. & 40 & $0.56 \pm 0.08 .10^{6}$ & 0 & $0.42 \pm 0.07 .10^{6}$ & 0 \\
\hline
\end{tabular}



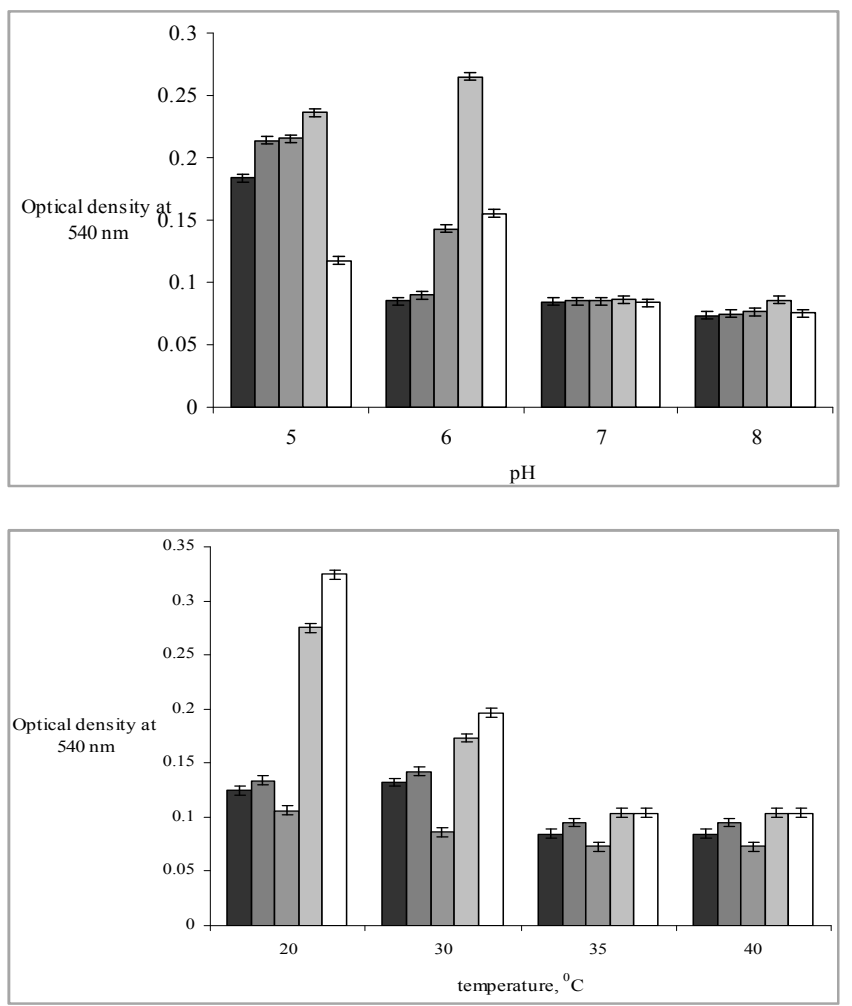

Figure 1. Effect of $p H$ and temperature on the growth of biofilms: $\boldsymbol{\square} B$. subtilis 170; - B. subtilis 168; - E. coli 1655; - B. subtilis 170+ E. coli 1655; $\square$ B. subtilis $168+$ E. coli 1655 .

Higher $\mathrm{pH}$ - value of culture media are created conditions for the emergence of antagonistic relationships, as result the biofilms are formed only with the participation of cells of the B. subtilis strains. The obtained values for the structure of the microbial population in the biofilms formed at a $\mathrm{pH}$ from 7,0 to 8,0 due to the fact that maintenance of $\mathrm{pH}$ - homeostasis in E. coli K-12 1655 strains in alkaline media is due to low activity of the system of antiport between sodium ions and protons, which determines their weak adaptive capacity under conditions of cultivation. On the another hand, the antagonistic activity of the B. subtilis 170 strain is associated with the creation of optimal conditions for action of secreted antimicrobial proteins whose biosynthesis is a function of the temperature of cultivation.

The temperature of cultivation influences on the growth of the biomass of biofilms formed by the participation of strains of B. subtilis and E. coli species, highest values are reported at $20^{\circ} \mathrm{C}$ (Figure 1). The reduction of the total biomass by increasing of temperature in the range from $30^{\circ} \mathrm{C}$ to $40^{\circ} \mathrm{C}$ is probably associated with the process of oxidation processes that leads to damage of the cell and cell proteins, chain of DNA [5-8]. Moreover, in the structure of the biofilm is established competitive relationships between the B. subtilis 170 and E. coli K-12 1655 strains at a temperature of cultivation of $20^{\circ} \mathrm{C}$, while the increasing of its value in the range from 20 to $40^{\circ} \mathrm{C}$ creates conditions for the development of antagonistic relationships, as a result of which the structure of the biofilm is dominated by cells of B. subtilis 170 strain, but the number of their colonies is decreasing from $32,4 \pm 0.13 .10^{6} \mathrm{cfu} / \mathrm{ml}$ to $0.42 \pm 0.07 .10^{6}$ $\mathrm{cfu} / \mathrm{ml}$ in the structure of the biofilm formed by cocultivation of pair of B. subtilis 170 and E. coli K-12 1655 strains (Table 1).

The osmolality of the medium influences on biofilm formation of a large number of bacterial species [9]. The increase of content of sodium chloride from $100 \mathrm{mM}$ to 200 $\mathrm{mM}$ results in a reduction of growth of the biomass of biofilms of B. subtilis 170 strain (Figure 2). The significant increase of numbers of cell population in the biofilm structure of E. coli K-12 1655 strain from $1 \pm 0,2.10^{3} \mathrm{cfu} / \mathrm{ml}$ to $12,53 \pm 0,21.10^{3} \mathrm{cfu} / \mathrm{ml}$ probably relates to the activation of transcription of the pga operon, which is responsible for the biosynthesis of proteins, necessary for the formation of polyacetylglucosamine, that is the part of the composition of the matrix [9,10]. Joint development with B. subtilis 170 strain doesn't $t$ determine its dominate role in the formation of structures of biofilms, given to the repression of genes for curly-fringe at the influence of products of life activity of strains of B. subtilis species. Accordingly, the content of sodium chloride of $200 \mathrm{mM}$ in the medium leads to absent of cells of the E. coli K-12 1655 strain in biofilms at his association with the strains of $\mathrm{B}$. subtilis species, which is an indication to perform the transition from competitive relationships to antagonism at increasing osmolality of the medium (Table 2).
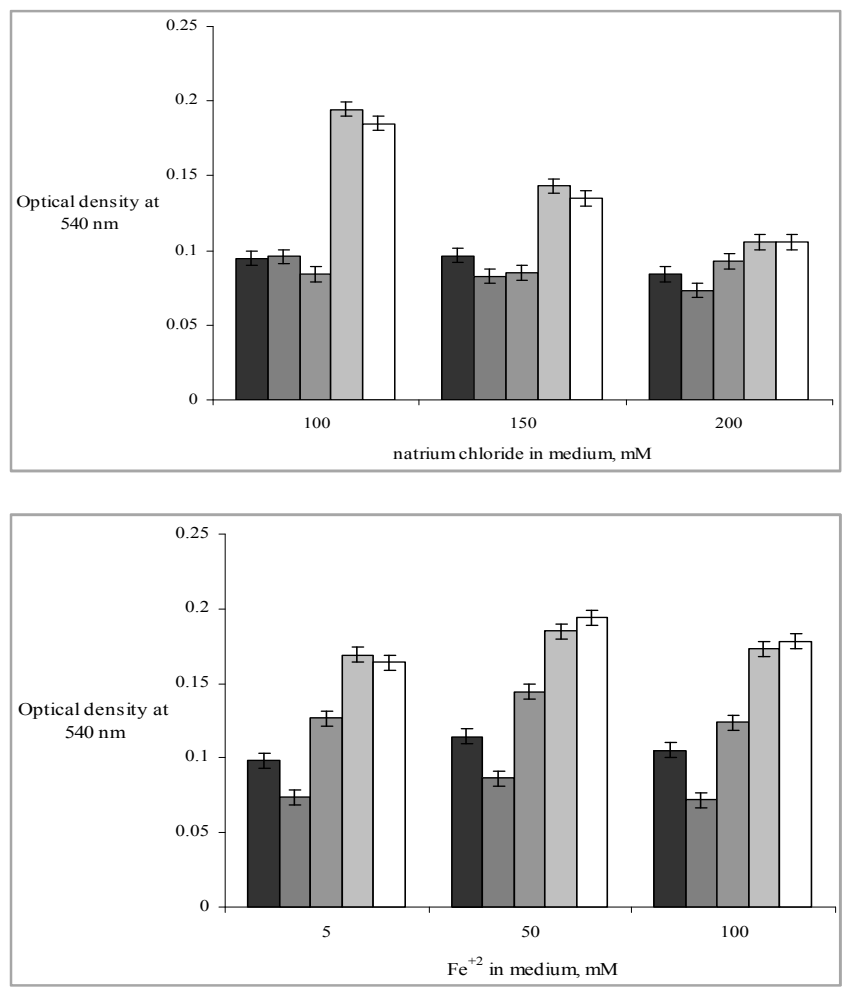

Figure 2. Effect of osmolality and $\mathrm{Fe}^{+2}$ of the medium on the growth of biofilms: - B. subtilis 170; - B. subtilis 168; - E. coli 1655; - B. subtilis 170+ E. coli 1655; $\square$ B. subtilis $168+$ E. coli 1655 . 
Table 2. Effect of concentration of sodium chloride in the medium on number of colonies of B. subtilis 170 and E. coli K-12 1655 strains in the structure of monospecies and mixed biofilms.

\begin{tabular}{|c|c|c|c|c|c|}
\hline \multirow{2}{*}{ № } & \multirow{2}{*}{$\begin{array}{l}\text { Concentration of } \mathrm{NaCl}, \\
\mathrm{mM}\end{array}$} & \multirow{2}{*}{$\begin{array}{l}\text { Number in biofilms of } B \text {. } \\
\text { subtilis } 170 \mathrm{cfu} / \mathrm{ml}\end{array}$} & \multirow{2}{*}{$\begin{array}{l}\text { Number in biofilms of E. coli K- } \\
121655, \mathrm{cfu} / \mathrm{ml}\end{array}$} & \multicolumn{2}{|c|}{ Number in mixed biofilms cfu/ml } \\
\hline & & & & B. subtilis 168 & E. coli K-12 1655 \\
\hline 1. & 100 & $36,5 \pm 0,62 \cdot 10^{3}$ & $1 \pm 0,2 \cdot 10^{3}$ & $116,43 \pm 0,97 \cdot 10^{3}$ & $31,56 \pm 0,32 \cdot 10^{3}$ \\
\hline 2. & 150 & $10,26 \pm .10^{3}$ & $0,22 \pm .10^{3}$ & $39,46 \pm 0,72.10^{3}$ & $21,13 \pm 0,21.10^{3}$ \\
\hline 3. & 200 & $10,3 \pm 0,26 \cdot 10^{3}$ & $12,53 \pm 0,21 \cdot 10^{3}$ & $13,5 \pm 0,3 \cdot 10^{3}$ & 0 \\
\hline \multirow{2}{*}{ № } & \multirow{2}{*}{ Concentration of $\mathrm{Fe}^{+2}, \mu \mathrm{M}$} & Number in biofilms of $\mathrm{B}$. & Number in biofilms of E. coli K-12 & \multicolumn{2}{|c|}{ Number in mixed biofilms $\mathrm{cfu} / \mathrm{ml}$} \\
\hline & & subtilis $170 \mathrm{cfu} / \mathrm{ml}$ & $1655, \mathrm{cfu} / \mathrm{ml}$ & B. subtilis 170 & E. coli K-12 1655 \\
\hline 1. & 5 & $4.63 \pm 0.3 .10^{3}$ & $4.83 \pm 0.30 .10^{3}$ & $42.96 \pm 0.40 .10^{3}$ & $5.23 \pm 0.15 .10^{3}$ \\
\hline 2. & 50 & $56.23 \pm 0.21 .10^{3}$ & $19.46 \pm 0.21 .10^{3}$ & $53.03 \pm 0.49 .10^{3}$ & $40.26 \pm 0.25 .10^{3}$ \\
\hline 3. & 100 & $4.5 \pm 0.2 \cdot 10^{3}$ & $5.43 \pm 0.32 .10^{3}$ & $102.93 \pm 0.29 .10^{3}$ & $8.86 \pm 0.15 .10^{3}$ \\
\hline
\end{tabular}

On the other hand, iron belongs to the trace elements, which content influences on the nature of relationships between strains of $\mathrm{B}$. subtilis and E. coli species during formation of biofilms [11]. The change of content of ferrous ions in the medium in the range from $5 \mu \mathrm{M}$ to $100 \mu \mathrm{M}$ is accompanied by the increase in biomass of mixed biofilms (Figure 2), optical density at $540 \mathrm{~nm}$ changed in a range from 0,163 to 0,184 as a result of the interaction between $B$. subtilis 170 and E. coli K-12 1655 strains. Low concentration of ferrous ions than $5 \mu \mathrm{M}$ in the medium catalyzes processes of intracellular accumulation of $\bullet \mathrm{OH}$, which reacts with biomakromolecules of cells [12] and provides a connection to cell surface protein in E. coli K-12 1655 strains and repression of genes for colonic acid biosynthesis, which explains their poor spread in the structure of biofilms at their interaction with B. subtilis 170 strain [10] (Table 2). The value of ferrous ion of $50 \mu \mathrm{M}$ stimulated symbiosis between investigated pair strains which may be attributed to the establishment of a balance between the generation of free radicals in cells of the both strains and the activity of superoxide dismutase enzyme systems, resulting in lowering the cytotoxic effect of the generated free radicals at both strains [13-15].

\section{Conclusions}

The effect of temperature of cultivation, $\mathrm{pH}$, osmolality, presence of $\mathrm{Fe}^{+2}$ on the growth of biofilms formed by a mixed population of strains of $\mathrm{B}$. subtilis and E. coli species was investigated. Temperature of $20^{\circ} \mathrm{C}$ and the $\mathrm{pH}$ value of the medium in the range from $\mathrm{pH} 5,0$ to $\mathrm{pH} 6,0$ maximally stimulate growth of biofilm biomass of $\mathrm{B}$. subtilis 170 and $\mathrm{E}$. coli K-12 1655 strains.

Changes of $\mathrm{pH}-\mathrm{value}$, the temperature of cultivation, osmolality of medium and the presence of iron ions affect the nature of the interaction between strains of $B$. subtilis and $E$. coli species in presen study, competitive relationships are observed at a temperature of $20^{\circ} \mathrm{C}$, the $\mathrm{pH}$ in the range from 5.0 to 6.0 at low osmolality of the medium of 100 to 150 $\mathrm{mM}$, at content of $\mathrm{Fe}^{+2}$ from $5 \mu \mathrm{M}$ to $100 \mu \mathrm{M}$. The increase of the temperature above $30^{\circ} \mathrm{C}$ and $\mathrm{pH}$ of the medium, high osmolality of $200 \mathrm{mM}$ triggers antagonistic interactions between test pairs strains, while at content of $\mathrm{Fe}^{+2}$ of $50 \mu \mathrm{M}$ was observed symbiosis during process of formation of biofilms.

\section{References}

[1] Elias S., E. Banin, FEMS Microbiol Rev, 36 (5), 990-1004 (2012).

[2] Moons P, Chris W. Michiels, A. Aertsen, Critical Reviews in Microbiology, 35(3), 157-168 (2009).

[3] Huang R., M. Li, R. Gregory, Virulence, 2 (5), 435-444 (2011).

[4] Martinez, R. Kitko, J. Patrick Mershon, H.. Adcox, K.. Malek, M. Berkmen, J. L. Slonczewski, Applied and Environmental Microbiology, 78(10), 3706 -3714(2012).

[5] Gambino M., F. Cappitelli, Biofouling, 32(2), 167-178 (2016).

[6] Grudeva V., P. Moncheva, S. Naumova, B. Gocheva, T. Nedeva, S. Antonova-Nikolova (2006). In: Manual of Microbiology; ("St. Kliment Ohridski” University Edition), Sofia, 146-153.

[7] Murata M, Fujimoto H, Nishimura K, Charoensuk K, Nagamitsu H, Raina S, Kosaka T, Oshima T, Ogasawara N, Yamada M., PloS One., 6, 20-63 (2011).

[8] Chen J, Shen J, Solem C, Jense, Appl Environ Microbiol., 79, 6140-6147(2013).

[9] Goller, C., X. Wang, Y. Itoh, T. Romeo, J. Bacteriol. 188, 8022-8032 (2006).

[10] Karatan E., P. Watnick, Microbiology and Molecular Biology Reviews, 73 (2), 310-347 (2009).

[11] Ryder C., M. Byrd, and D. J. Wozniak, Curr. Opin. Microbiol., 10,644-64 (2007).

[12] Bokare AD, Choi W., J Hazard Mat, 275, 121-135(2014).

[13] Cabiscol E, Tamarit J, Ros J., Intern Microbiol., 3, 3-8(2000).

[14] Green J, Paget MS., Nat Rev Microbiol., 2, 954-966 (2004).

[15] Imlay J., Curr Opin Microbiol., 24, 124-131 (2015). 